\title{
Cadavre Exquis
}

\section{A Motion-Controlled Interactive Film}

\author{
Bruno Mendes da Silva \\ CIAC/UAlg \\ Portugal \\ bsilva@ualg.pt
}

\author{
António Bandeira \\ Araújo \\ $\mathrm{CIAC} / \mathrm{UAb}$ \\ Portugal \\ antonio.araujo@uab.pt
}

\author{
Mirian Tavares \\ CIAC/UAlg \\ Portugal \\ mtavar@ualg.pt
}

\author{
Susana Costa \\ CIAC/UAlg \\ Portugal \\ srsilva@ualg.pt
}

\begin{abstract}
This interactive film, a variation on the surrealist game Cadavre Exquis, seeks the possibility of subverting the filmic discourse by exploring psychosomatic processes that may give the viewer different perceptions of cinematic time, by providing the possibility of intervening into the narrative in a disruptive way.
\end{abstract}

\section{CCS CONCEPTS}

\section{- Media Arts}

\section{KEYWORDS}

Interactive Film, Time, Cadavre Exquis

\section{ACM Reference format:}

Silva Bruno, Araujo António, Tavares Mirian e Costa Susana. 2019. Cadavre Exquis - A Motion-Controlled Interactive Film. In Proceedings of Artech 2019, 9th International Conference on Digital and Interactive Arts (Artech 2019). Braga, Portugal, XX pages. https://doi.org/10.1145/3359852.3359933

\section{Introduction}

The film Cadavre Exquis is part of the project The Forking Paths, which is available in an online platform (oscaminhosquesebifurcam.ciac.pt) dedicated to interactive film experiments. In addition to other experiments, the platform includes the films produced for the project: Valsa (2016), The Book of the Dead (2015) and Haze (2014). The aim of this project is to conduct an original research targeting the discovery of potential new knowledge, namely through practice and through the results of this practice. The Forking Paths platform intends to bring together experimental interactive films of different origins, genres and formats that seek to develop innovative connections between the spectator-user and the narrative. Ultimately, this project, in particular the interactive film Cadavre Exquis, seeks for clues that may lead to possible paths within the evolution of audiovisual language.

\section{Interactive models}

Claiming the title of "the first interactive film" in the history of interactive film and one of the most successful is the Czechoslovakian film Kinoautomat - one man and his house, created in 1967 by Radúz Činčera, for the World Expo in Montreal. In this film, the audience is asked (nine times) to choose one of two given possibilities to continue the narrative. At the first screening in Montreal, the process of choice was mediated by an actor. Dozens of interactive films have been made since than and we find the need to classify all those experiences. Therefore, we tried to find a set of models capable of including all interactive films: (a) the arborescent model, based on a simple one-off choice made at certain moments in the narrative, where the viewer can choose paths A or B, for which we may use the film Last Call as an example; (b) the constructive model, which involves multiple interpretation, according to the options offered by the project, where we can include the experimental film Haze; (c) the paired model, which allows the incorporation of content external to the narrative, as in the film Take This Lollipop; and (d) the fertile model, whose process of interaction between spectator and film entails the creation of new content, although such a film does not yet exist. 


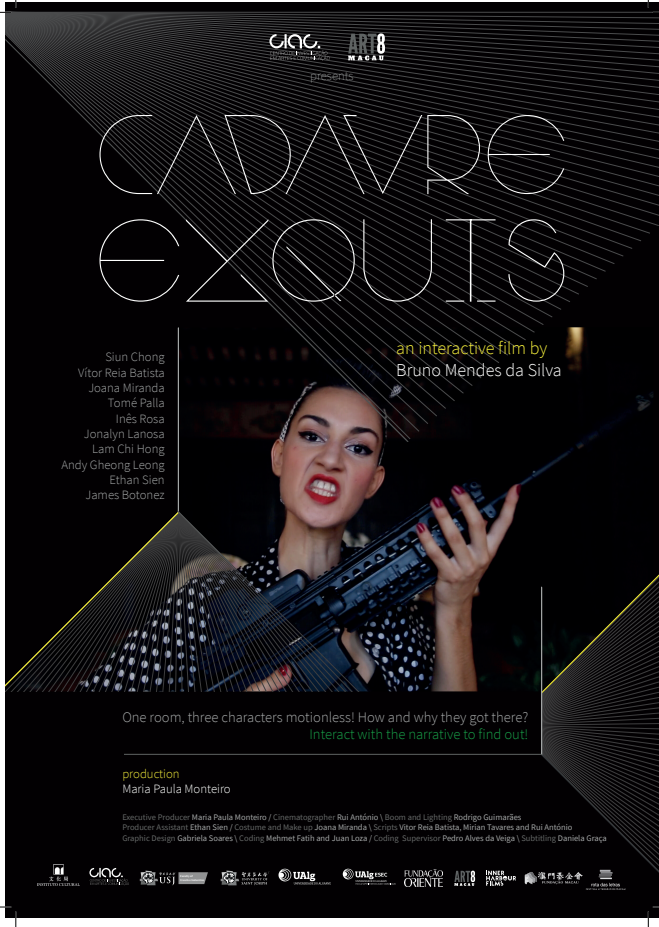

Figure 1: Movie Poster

\section{Time}

A key issue in this project is time: time in cinema. As theoretical basis, the notions of movement-image, time-image and crystalimage, proposed by Deleuze, serve as structural basis for this work. By appealing to viewer immersion, they cause a reaction contrary to the usual passive-submissive reaction. According to Deleuze [2], the sensory-motor sensations, indirect representations of time, tend to be replaced by exclusively visual and audible conjunctures, namely the opsign ${ }^{1}$ and the sonsign ${ }^{2}$, direct representations of time.

\section{Cadavre Exquis}

Three scriptwriters were invited to create three narratives based on a character who, at the end of the narrative (24 hours later, at most), would meet two other characters in a room. The scripts would form a succession of sub-narratives which, just as in the Cadavre Exquis game, converge in the main narrative, eventually ending up in a succession of unlikely scenes. A common opening scene was added: the scene of the three characters in the same room. The sequencing of ideas in the film does not obey a discursive logic, presenting itself as "une construction où on n'emploierait ni joints ni ciment"[1]. Meaning and syntax diverge

\footnotetext{
${ }^{1}$ Purely optical description, where the spectator (the one who watches) replaces the protagonist (the one who acts).

${ }^{2}$ Purely auditory description, the same principle of opsign.
}

often, causing a rupture in speech, which is amplified even more by the very particular use of punctuation, to the extent of utterly suppressing it in certain parts. The opening scene of the film Cadavre Exquis is frozen (stopped in time). Three characters meet in the same room. However, the viewer has the possibility to travel through the freeze-frame, getting closer to or moving away from each character.

When the viewer gets closer to a character he/she may select him/her. That choice results in a flashback, at most 24 hours, which leads up to the frozen moment. By choosing the last character the viewer will unfreeze the opening scene, setting it in motion. Barry Dainton [3] summarizes the different proposals of the structure of temporal consciousness into three models: Retentional Model, Extensional Model and Cinematic Model. In the Retentional Model, the experience of change and succession occurs in episodes of consciousness, whose contents represent temporally extended intervals, despite the lack of temporal extension. These episodes have a complex structure and comprise the momentary phases of immediate experience as well as the retentions of the recent past. The streams of consciousness are thus composed of successions of these momentary states. In the Extensional Model, the episodes are themselves temporarily extended and are able to incorporate changes. The streams of consciousness are composed of successive episodes of extended experience. Finally, in the Cinematic Model, immediate perception lacks any temporal extension. The same applies to the contents we are directly conscious of, which somehow resemble photograms. The stream of consciousness is thus composed of a continuous succession of momentary states of consciousness, hence resembling films that consist of frame sequences. The idea of a freeze-frame (of the opening scene) is just that: a frame with no sequence. However, in the film (Cadavre Exquis) the viewer can travel through the photogram, giving it a sequence: a possibility of a past and a future, or better, a possibility of new present frames taking place after or before the initial photogram. The aim is to achieve a relaxation and a reconstruction of the idea of time in cinema, where the relation between space and time is overruled by an eminently oneiric temporal dimension.

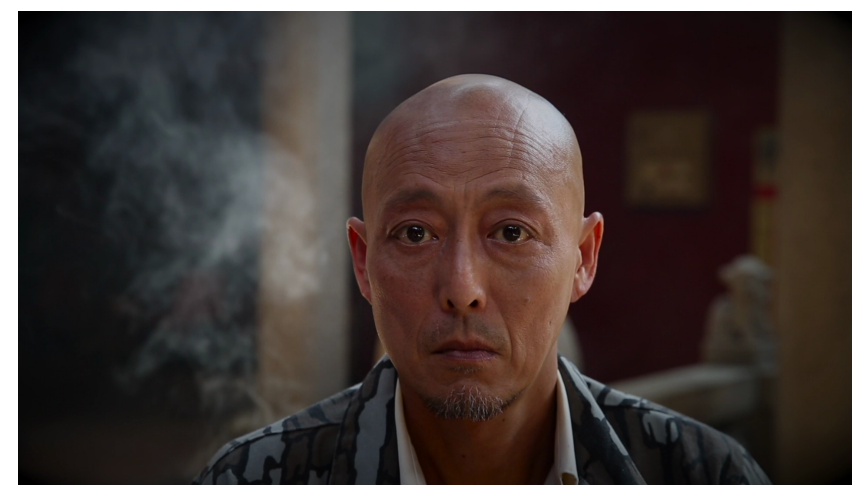

Figure 2: Frame from the interactive film Cadavre Exquis

\section{Description of the Installation}


The installation requires of a computer, a Kinect sensor, a computer screen, a stand with printed signage, a table. The screen lies on the table, and in front of it lies the sensor, near the edge of the table. The technical ensemble is made discrete by a black cloth that blends with the sensor and hides the computer, under the table (Figure 3). The ensemble is to be experienced by a single user at a time, so it must be enclosed in a space where the sensor will ignore the presence of other people. Ideally it should be enclosed on a square of between $2 m$ and $3 m$ side length, depending on the size of the screen itself. For instance, the first version of the installation, displayed in the 2019 Literary Festival of Macau, was contained inside a square tent of $2 \mathrm{~m}$ side length (that itself appears in a scene of the film), and the screen measured about $1 \mathrm{~m}$ by $1,05 \mathrm{~m}$. For the present installation, if it is to be on a shared room, a corner of a room would be the ideal spot for avoiding sensor disturbances; ideally then, the ensemble sits at a corner of a room defining an enclosed square, of between $2 m$ and $3 m$ side length, walls defining two sides, the table defining a third side, and the user entering the confined space by the fourth side, lateral to the sensor (Figure 3). At this "entrance" stands printed signage that explains the interaction with the sensor (Figure 4). As users cue to enter, they can take a moment to become familiar with it.

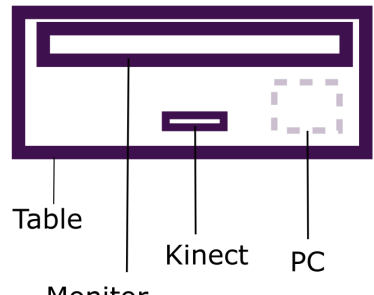

Monitor

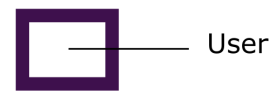

Figure 3: Plan view of the installation.

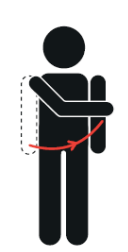

SELECT LEFT: right hand slides to the left
ight hand slides

如果選擇用右手， 請以右手向左揮一揮

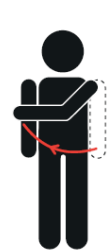

SELECT RIGHT: left hand slides
to the right

如果選擇用左手 請以左手向右揮一揮
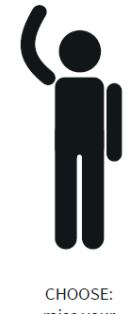
raise your
right hand 選擇舉起右手

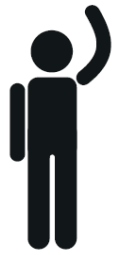

BACK TO START: raise your
left hand

手放回來， 手放回來,
舉起左手
Figure 4: Signage of the Macau installation.

It shows pictures of the following motions:

1. Right hand swipes left: pan camera to the left

2. Left hand swipes right: pan camera to the right

3. Right hand held up: Select character

4. Cross hand above head: Fast Forward

5. Left hand held up: Reset

As the user enters the space in front of the sensor, he is greeted on the screen by a short film: a panning motion that shows on the screen the view of a room on which three seated characters can be seen. As the user takes his place at the center of the square (marked on the ground with tape), he can experiment with the motions learned from the signage. He will find that the swiping arm motions control the panning motion of the film. Swiping left or right puts the user in the director's place, controlling and altering a panning shot, and thus centering the view on any of the three characters in the room. Raising his right hand, the user will trigger the short film of whatever character is currently in focus.

Once the short film is playing, the user may simply watch it, or fast forward through it by crossing hands above his head. For two of the three characters, as the short film ends, the user will find himself back in the room, focusing on the chosen character, and able to choose another by panning again. When the third character is chosen, however, the film's ending will trigger a change in the very room that holds the characters. The user will return to a sweeping view of the room, in which he will glimpse that the third character is now gone from his chair, replaced by a new one. This new character carries his own associated short film, that provides a concluding note to the experience.

\section{Technical Implementation}

The program that controls the interactive film was developed in Processing [4], an open-source graphical library and integrated development environment for the Java programming language, well-known among digital artists. The main form of user input was body motion, detected through a Microsoft Kinect, and this was programmed through the KinectPV2 (Kinect for windows v2) Processing library [5]. The Microsoft Kinect is a motion sensing input device produced by Microsoft, originally designed as a gaming input device. We used the 2013 Kinect for Xbox 360 version with a PC adapter. This version can capture video at 1080p, has an IR sensor, and can track the motion of up to 6 users, with 25 joints tracked per skeleton. Kinect can make heavy demands on the hardware requirements (it needs a USB 3.0 interface and a fast $\mathrm{CPU} / \mathrm{GPU}$ ) but we designed the program to ask for as little processing power as possible. To this end, motion detection was kept to the simplest and most robust - this was not only inspired by technical needs but from a sense of pleasure in misdirection. The user is led by the printed signage to think that his whole swiping hand movement is being followed but in fact detection only happens upon a single static condition: for instance, in motion 1 (right hand swipes left) the only test actually 
performed is whether the left hand is to the left of the left hip. This is a static condition, tested at the easiest moment of the swipe, as the pendulum motion of the arm reaches the top and stops for a split second; and yet the user is led to feel by his brief instruction - which is important for the fruition of the experience - that the whole sweeping motion is an integral part of the process. Such acts of misdirection, although initially done for technical reasons (weak hardware) soon became a point of interest for our research, and it was with great interest that we observed first that the misdirection almost always worked, but also what interesting inventions users came up with in the few cases where they detected the ruse, and proceeded to experiment with the motions, trying to reverse engineer the hidden workings.

\subsection{Software Implementation - a Finite State machine}

The computer program that controls the interactive film is implemented as a finite state machine [6]. At each moment the program it at one of several predefined states, and it transitions from one of those states to another depending on the result of a number of tests, by querying either system variables or user input: for instance State 0 is the state where the camera gives the original overview of the room. This is a mini-film in itself, during which interaction is unavailable. The state terminates when the film reaches its end, and then the finite state machine transitions to state RICl (meaning Room 1 Character 1), where the camera is fixed on the first character in the initial room (or rather in the initial moment of the room, the second moment being when the third character has been replaced). This state gives access to state RIC1_to_R1C2 (if the user raises swipes the right hand), in which we see the panning movement to character 2 , or to state PlayR1C1, where the user watches the short film of character 2. These states in turn have their own tests that lead to other states, and so forth.

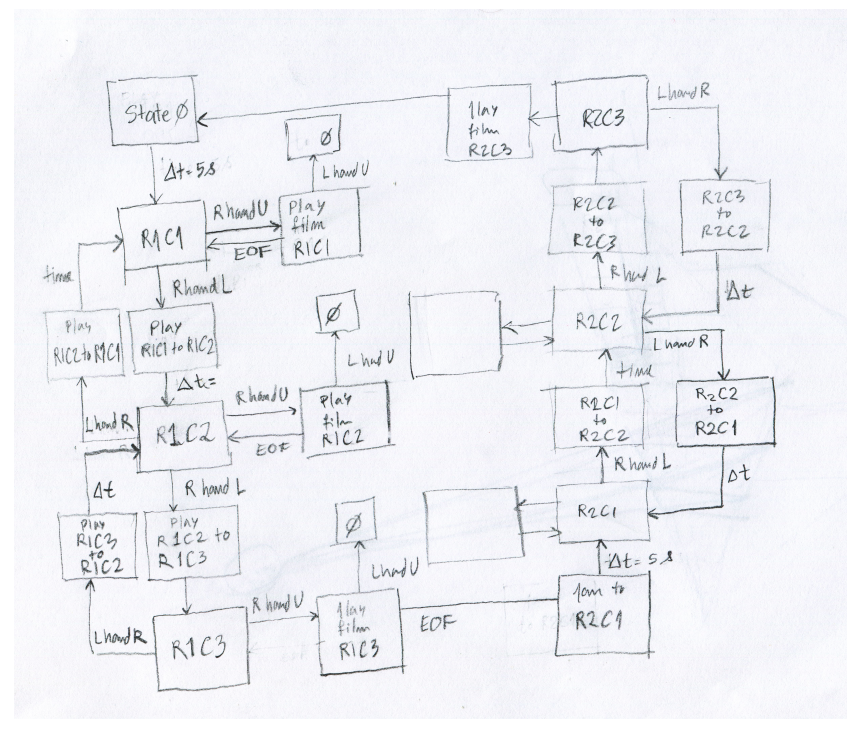

Figure 5: Early sketch of the finite state machine controlling Cadavre Exquis

\section{Material Requirements}

The authors will supply the computer and the Kinect sensor. The spatial requirements are a square space, of between $2 m$ and $3 m$ size at a corner of a room. It would be helpful if a table could be provided by the organizers, together with a screen of about $1 \mathrm{~m}$ by $1,05 \mathrm{~m}$. These requirements can be adapted to accord with circumstance.

\section{Conclusions}

Cadavre Exquis seeks a certain evolutionary trend regarding audio-visual language. Although the morphological issues remain unchanged, we found signs that appear to indicate a possible evolution within the audio-visual syntax, such as the fragmenting of the unity of time and space. It is important to remember the role of the viewer, who not only becomes an active part in the narrative but can also undertake the task of co-authoring. It is also necessary to underline the importance of academic experimentation, which should, whenever possible, go beyong theorizing and involve a praxis through a demonstration of the developed theories. Within the scope of the models found (arborescent model, constructive model, paired model and fertile model), the possibility of generating new content (fertile model) through the interaction man-machine is regarded as the most likely possibility of rupture and the development of a new generation of interactive movies.

\section{ACKNOWLEDGMENTS}

CIAC, Art8, UALG, UAb, USJ, Instituto Cultural de Macau, Fundação Oriente, Fundação Macau, Inner Harbor Films, The Script Road Fest and FICLO.

[1] Breton, André. 1972. Manifestes du surréalisme. Paris, Gallimard.

[2] Deleuze, Gilles. 1990. A Imagem-Tempo. São Paulo, Brasiliense.

[3] Dainton, Barry. 2010. Time\&Space. NY, Routledge.

[4] Processing. https://processing.org/ (last accessed June 2019)

[5] KinectPV2 library. https://github.com/ThomasLengeling/KinectPV2 (last accessed June 2019)

[6] Rich, Elaine A. 2007. Automata, Computability and Complexity: Theory and Applications. NJ, Pearson Prentice-Hall. 